\title{
Author Correction: A practical framework and online tool for mutational signature analyses show intertissue variation and driver dependencies
}

Andrea Degasperi, Tauanne Dias Amarante, Jan Czarnecki, Scott Shooter, Xueqing Zou, Dominik Glodzik, Sandro Morganella, Arjun S. Nanda (1D, Cherif Badja, Gene Koh (1D, Sophie E. Momen, llias Georgakopoulos-Soares, João M. L. Dias, Jamie Young, Yasin Memari, Helen Davies and Serena Nik-Zainal $\mathbb{D}$

Correction to: Nature Cancer https://doi.org/10.1038/s43018-020-0027-5, published online 17 February 2020.

In the version of this article initially published, the following statements were missing from the Acknowledgements section: "We would also like to thank the International Cancer Genome Consortium for access to WGS primary cancer data. This work has been facilitated by Hartwig Medical Foundation (HMF) and the Center for Personalized Cancer Treatment (CPCT), which have generated and made available metastatic whole cancer genome data for this research." The error has been corrected in the HTML and PDF versions of the article.

Published online: 17 June 2020

https://doi.org/10.1038/s43018-020-0093-8

(c) The Author(s), under exclusive licence to Springer Nature America, Inc. 2020 